\title{
Reviving the industry system construct: a look at the 5G network equipment manufacturing industry
}

\author{
Rick Randall, The MITRE Corporation, rrandall@mitre.org \\ Michael Heffner, The MITRE Corporation,mheffner@mitre.org \\ Vinay Lakshminarayan, The MITRE Corporation, vinay@mitre.org
}

\begin{abstract}
The purpose of this paper is to investigate the feasibility of applying systems theory to the analysis of contemporary technology industries. Since the 1960s, social science scholars have recognized organizations as being open systems which import information and material resources as inputs, apply processes to convert input materials into intermediate and final work products, and then provide outputs to their surrounding environment. A relatively straight-forward logical extension of viewing organizations as open systems is to view an industry as an open system, where the system elements of the industry include organizations and the mechanisms that govern interorganizational relations in an industry, such as supply chains, industry alliances, and industry trade associations. Surprisingly, there is little contemporary literature which takes this view of industries as definable systems. This conceptual paper reintroduces the idea of industries as systems, examines the fifth generation $(5 \mathrm{G})$ wireless network equipment manufacturing industry as an example of an industry system, and offers a research agenda for defining mid-level theories in this area.
\end{abstract}

Keywords: Industry system; Business ecosystem; System of Systems; Big data

\section{Introduction}

Fifth generation wireless mobile telecommunications, or " $5 \mathrm{G}$ ", has been lauded by technology pundits as ushering in a new era supporting mobile broadband speeds 600 times faster than $4 \mathrm{G}$, enabling massive Internet of Things (IOT) connectivity of up to one million devices per square kilometer, and providing ultra-reliable low delay communications that can enable applications such as virtual reality and self-driving vehicles (Jabagi, Park, \& Kietzmann, 2020). Our interest in understanding the makeup of the $5 \mathrm{G}$ telecommunications infrastructure equipment manufacturing industry was prompted by a 2019 Washington Post newspaper story which asserted that "Barely any U.S. companies manufacture the technology's most critical components" (Fung, 2019, para 2). Concern over this apparent state of affairs led to two research questions that we explore in this conceptual paper: One, what is the current makeup and structure of the $5 \mathrm{G}$ telecommunications infrastructure network equipment manufacturing industry, and Two, how can the application of systems theory aid in understanding the industry?

Technologically, the question of "What is $5 G$ " is answered by the standards specifications published by a collective of seven regional standards development organizations (SDOs) known as the Third Generation Partnership Project, or 3GPP (3GPP, 2021; Baron \& Gupta, 2018; Teubner, Henkel, \& Bekkers, 2021). Organizationally, 3GPP is structured into three Technical Specification Groups and 15 Working Groups (3GPP, 2021), and is supported by 22 "Market Representation Partner" organizations (3GPP, 2020) providing stakeholder inputs from affected downstream industries such as the automotive and satellite industries. Functionally, the interactions of the member organizations comprising the seven regional SDOs are complex and deserving of further study in their own right. In this paper, we view 


\section{Issues in Information Systems}

Volume 22, Issue 3, pp. 320-334, 2021

SDOs as being system elements or components of a larger social system having distinct and analyzable properties - an industry system, as explained in Section 2.

The benefit of using systems theory to study large scale phenomena is that an analyst can synthesize observations of structures, functions, and processes to produce a coherent understanding of a 'whole' (Gharajedaghi, 2011). The example 'whole' presented in this paper is a high-level view of the 5G telecommunications network equipment manufacturing industry. This industry is involved in contemporary controversies involving national security and supply chains.

The remainder of this paper is structured as follows: Section 2 provides a literature review of theoretical constructs we examined pertaining to systems, organizational systems, and industries. Section 3 describes the exploratory data set we collected for formulating our research agenda. Section 4 offers analytical discussion of viewing the selected industry as a system. Section 5 identifies the implications and limitations of the paper. Section 6 presents a conclusion and a research agenda for advancing the ideas presented.

\section{Theoretical background}

In this section, we provide a high-level summary of literature streams influencing our analytical approach: Industry studies, organizational systems, business ecosystems, large technical systems, and systems of systems. Space limitations of the paper prevent us from performing an exhaustive review of these topics, and hence we instead provide summaries of the key issues from each topic and provide citations to more extensive literature reviews performed by previous authors.

\section{The study of industries}

Porter (1990) defines an industry as "a group of competitors producing products and services that compete directly with each other." (p 33). Scott (2008) avoids Porter's emphasis on competition, defining an industry simply as "a population of organizations operating in the same domain as indicated by the similarity of their services or products" (p. 86). Crowston and Myers (2004) explain that three distinct disciplinary paradigms have been used to study industries: The economics paradigm exemplified by Porter, the institutional paradigm espoused by institutional theorists such as Scott, and a socio-cultural paradigm promoted by authors from the sociology and organizational studies disciplines. The divergent ways that Porter and Scott define the term "industry" highlights the differences in philosophical orientations between the economics and institutional paradigms.

Chiasson and Davidson (2005) identified seven distinguishing features for performing industry-level analysis of information systems (IS) phenomena using case study methods: Technology, market structure, supply-side factors, demand-side factors, institutional actors, institutional logics, and governance systems (pp. 593-595). The technology factors of an industry can be studied using disciplines such as systems engineering and computer science. Supply-side and demand-side factors are studied in disciplines such as business strategy and economics, and also appear in specialized topical areas such as supply chain management (Dedrick, Kraemer, \& Linden, 2011; Kim, Ryoo, \& Jung, 2011; Sun \& Rose, 2015). The topics of institutional actors, institutional logics, and governance processes often appear in studies analyzed from the perspective of institutional theory (Auschra, Schmidt, \& Sydow, 2019; Beckert, 2010; Rowley, Behrens, \& Krackhardt, 2000). Hence, performing a substantive analysis of an industry can become a challenging cross-disciplinary endeavor.

\section{Organizational Systems}

Ludwig von Bertalanffy (1968) created the IS theory known as general system theory (GST) as a means of describing the commonalities of phenomena ranging from atoms and molecules to planets, solar systems, and galaxies. Bertalanffy (1968) defines a system generically as "A set of elements standing in interrelation among themselves and with the environment" (p. 417). Bertalanffy (1972) defines two 


\section{Issues in Information Systems}

Volume 22, Issue 3, pp. 320-334, 2021

approaches for developing scientifically rigorous system descriptions: internal description, based on the structure and components of the system of interest, and external description, based on functional and behavioral interactions between the system of interest and its environment (1972, p.420). He defines nine common properties of systems, which we elaborate upon in Table 1 below: Allometry, centralization, competition, equifinality, finality, growth, mechanization, sum, and wholeness (Bertalanffy, 1968, pp. 62-79).

Table 1: GST properties (Bertalanffy, 1968)

\begin{tabular}{|c|c|}
\hline $\begin{array}{l}\text { Property of General } \\
\text { Systems }\end{array}$ & Definition from (von Bertalanffy, 1968) \\
\hline Allometry & $\begin{array}{l}\text { "Relative growth rates ... stand in constant proportion" (p. 64) } \\
\text { (This property was referred to as "isomorphism" in later GST } \\
\text { writings) }\end{array}$ \\
\hline Centralization & $\begin{array}{l}\text { One element becomes "a leading part... the system is centered } \\
\text { around it" (p. 71) }\end{array}$ \\
\hline Competition & $\begin{array}{l}\text { "Every whole is based upon the competition of its elements, and } \\
\text { presupposes the struggle between parts" (p. 66) }\end{array}$ \\
\hline Equifinality & $\begin{array}{l}\text { "...the same final state can be reached from different initial } \\
\text { conditions and in different ways." (p. } 79)\end{array}$ \\
\hline Finality & $\begin{array}{l}\text { [1] "Fitness ... useful for a certain purpose;" [2] Purposefulness } \\
\text { "based on structure" (pp. 77-78) }\end{array}$ \\
\hline Growth & $\begin{array}{l}\text { "In social science, it is called the law of Malthus, signifying growth } \\
\text { of population... It also describes the growth of human knowledge, as } \\
\text { measured by textbook pages devoted to scientific discoveries" (p. 62) }\end{array}$ \\
\hline Mechanization & $\begin{array}{l}\text { "Disturbance of the system leads to a new state of equilibrium." } \\
\text { "...performance of each region depends on its position within the } \\
\text { whole" (1968, p. 68) }\end{array}$ \\
\hline Sum & $\begin{array}{l}\text { "The variation of the total complex is the sum of the variation of its } \\
\text { elements" (p. 67) }\end{array}$ \\
\hline Wholeness & $\begin{array}{l}\text { "You have to take into account the relations between the various } \\
\text { subordinated systems ... to understand the behavior of the parts." (p. } \\
68 \text { ) }\end{array}$ \\
\hline
\end{tabular}

Boulding (1956), a contemporary of Bertalanffy, conceived of a hierarchy of eight levels of systems, where higher level systems are comprised of embedded entities from the lower level systems. Boulding termed level seven of his systems hierarchy to be social organizations, and argued that the systems at this level are immensely more complex and difficult to analyze than lower level systems (Boulding, 1956, p. 207). Social science scholars in the 1960s and early 1970s (Kast \& Rosenzweig, 1972; Katz \& Kahn, 1966; Lawrence \& Lorsch, 1967) developed constructs for describing organizations of humans as open systems, citing the works of Bertalanffy and Boulding as references. Parsons (1960), a sociologist, conceived of a simple and powerful framework for categorizing the subsystems within the organizational system of any non-trivially sized organization. Parsons' (1960) organizational system framework comprises three layers: The technical subsystem, which comprises the functional work processes and technologies which produce the organization's primary products, the managerial subsystem, which comprises functions for administering the organization (such as human resources, accounting, and procurement), and the institutional subsystem which defines the organization's de facto 


\section{Issues in Information Systems}

Volume 22, Issue 3, pp. 320-334, 2021

governance policies and culture. Thompson (1967) adopted Parson's framework in his seminal book describing uncertainties and decision making processes in corporations.

Hirsch (1972) extended the constructs of Parsons (1960) and Thompson (1967) by defining the notion of an industry system. An industry system, per Hirsch, is comprised of technical systems in the form of companies that create products, managerial systems in the form of marketing, distribution, and financial services organizations supporting the product companies, and an institutional system which defines the regulations and cultural norms of the industry. In this paper, we argue that Hirsch's construct is timely and relevant for studying contemporary industries such as the $5 \mathrm{G}$ network equipment industry.

\section{Three frameworks for describing system elements of an industry}

We have chosen three conceptual frameworks having the word "system" in their names as illustrations of GST realization in use: Business ecosystems (BE), large technological systems (LTS), and system of systems (SoS). We provide a summary of each framework in the sections below.

The BE, LTS, and SoS frameworks each emerged in a different research context and have followed different evolutionary paths from the others after their introduction. At the same time, there are overlapping concepts between the three frameworks. For example, both BE and LTS posit the importance of history in informing deep understanding - LTS being fundamentally grounded in research on the history of socio-technical systems (van der Vleuten, 2009, pp 218-219) and BE research using history to inform current business strategy and decision-making (Moore, 1996, p. 85). To be clear, we are not proposing that each of these frameworks is a direct outgrowth of GST; rather, we are using GST as a metamodel in our discussion to perform apples-to-apples comparisons.

\section{Business ecosystems}

A business ecosystem can be defined as "A community of hierarchically independent, yet interdependent heterogeneous organizations that collectively generate an ecosystem output" (Thomas \& Autio, 2020). Moore (1993) is credited with coining the term 'business ecosystem,' but his seminal Harvard Business Review article largely neglects discussion of earlier multi-organizational relationship literature streams such as population ecology (Hannan \& Freeman, 1977), organizational fields (DiMaggio \& Powell, 1983), and interorganizational networks (Aldrich \& Whetten, 1981; Monge \& Contractor, 1987) that bear similarities to the BE construct. The task of comparing and contrasting BEs to these alternative frameworks fell to later ecosystem scholars (Adner, 2017; Mäntymäki \& Salmela, 2017; Oh, Phillips, Park, \& Lee, 2016; Scaringella \& Radziwon, 2018).

$\mathrm{BE}$ evolved as an alternative to analysis of an individual business entity competing within a narrowly defined industry (Moore, 1996). Instead, the BE viewpoint uses a biological metaphor to consider multiple entities coevolving within a "wider economic ecosystem and environment" (p. 8). Layers or rings of the model begin with a "core business" built on "core capabilities" and including direct suppliers and distributers, expanding to an "extended enterprise" that folds in standards bodies, second tier suppliers, direct and secondary customers, and suppliers of complementary products and services. (p. 27). Möller et. al, in their article proposing an integration of ecosystem, interorganizational network, and organizational field concepts, suggest that the BE construct resides at two mid-level or meso layers in between firms at a micro level and societies at a macro level (Möller, Nenonen, \& Storbacka, 2020).

\section{Large technological systems}

The LTS framework emerged from the work of Hughes (1983), who was broadly interested in the history and sociology of technology (van der Vleuten, 2009, p. 218). LTS are defined as "sociotechnical networks ... comprised of social processes in which multiple and heterogeneous actors 
interact and work together" (Dutton, Schneider, \& Vedel, 2011, p. 2). The LTS research stream has shown a particular interest in large infrastructure and production systems, such as electricity networks, railroad networks, and telecommunication networks (Dutton et al., 2011). LTS research has been driven by two concerns: First, to move beyond a focus on specific technological developments and their effects to study of the larger systems that incorporate those technologies and associated "deep structures" in society (van der Vleuten, 2009, pp. 218-219). Second, to understand systems in terms of their sociotechnical nature and relationship to societal change. Early studies focused on centrally managed utilities such as electricity supply but later expanded to loosely-coupled systems such as transportation (p. 219). Hughes and subsequent researchers identified a pattern of LTS development with overlapping phases (the numbers are ours): I. invention, II. development, III. innovation, IV. competition and growth, V. consolidation, VI. technology transfer (which can occur in parallel with any phase), and VII. Stagnation. The concept of system-builders, individuals and organizations that drive the creation and evolution of the sociotechnical system, is core to the LTS approach (pp. 219-222). Users also are instrumental in system evolution and propagation of societal effects.

\section{System of systems}

SoS began as a loose set of ideas developing primarily in systems engineering disciplines, especially as applied to large military, industrial and infrastructure capabilities (Maier, 1998). To better support the architecture definition of these large, complex structures, Maier proposed a more specific definition of SoS as a group of collaborative systems, a taxonomy for categorizing SoS, and a set of architecting principles. Key to the definition of SoS are the concepts of operational and managerial independence of the components comprising the SoS. Maier (1998) defined three types of SoS (1998), subsequently extended by Dahmann and Baldwin (2008) with a fourth type: directed, virtual, collaborative, and acknowledged. Maier (1998) also presents a set of architectural principles that engineered SoS should exhibit: stable intermediate forms, policy triage, leverage at the interfaces, and ensuring cooperation. Maier also posits that architecture is "largely defined by a communications model" (p. 288). While early work on defining SoS is concentrated on architectural attributes of the technology itself, we see in more recent work an expansion of SoS concepts to the larger environments and surrounding social structures which define the sociotechnical context of a system (Cook \& Pratt, 2016; Dahmann \& Baldwin, 2008; Randall \& Heffner, 2019). The work on SoS has been running in tandem with that on complex systems (Cilliers, 2001; Mitleton-Kelly, 2003). An IEEE working group proposed that SoS is a specific subset of complex systems differentiated by the defining characteristics of organizational and managerial independence (Dersin, 2014).

\section{The 5G network equipment manufacturing industry}

We initiated our study of the $5 \mathrm{G}$ telecommunications network equipment manufacturing (NEM) industry using an inductive industry-level case study research methodology as recommended by Jacobides (2005), including the use of annual reports of key firms, government reports and regulations, industry-specific academic research, and industry trade journal news stories as source materials. One initial difficulty we encountered in our exploratory investigation was defining the industry boundary of what was inside of, and what was external to, that industry (Bray \& Waring, 2009; Fixson \& Park, 2008). We adopted the following definition of NEM from a vocabulary document from a test equipment vendor: NEMs are "Firms that build network equipment for service providers to manage their networks" (Keysight Technologies, 2019, p. 8). One straightforward way of differentiating NEMs from other types of firms involved in telecommunications, such as mobile network operators (MNOs), is to match firms to North American Industry Classification System (NAICS) classification code definitions (U.S. Census Bureau, 2017). NEMs such as Ericsson, Huawei, and Nokia are associated with NAICS subsector 3342, Communications Equipment Manufacturing, whereas MNOs such as AT\&T, Verizon, and Vodaphone as associated with NAICS subsector 5173, Wired and Wireless Telecommunications Carriers (U.S. Census Bureau, 2017). These business model differences are presented in the form of a value chain in 
Figure 1, with suppliers of NEMs (such as the semiconductor and electronics industries) depicted on the left hand side of the figure, and MNOs and their customer segments depicted to the right of the NEMs.

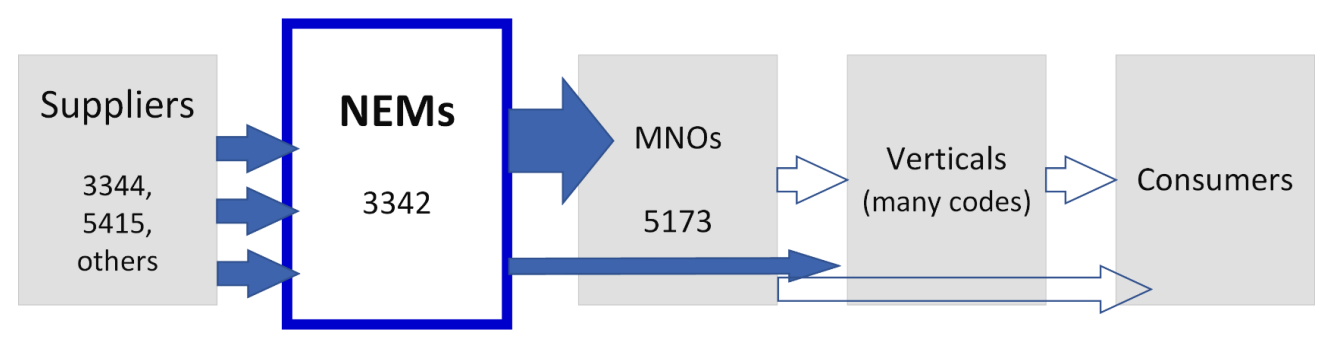

Figure 1: 5G NEM value chain, with applicable NAICS subsector codes

We began our research by seeking out existing market studies of NEMs from firms such as Gartner and Forrester Research, in accordance with the Jacobides (2005) case study approach. Gartner (2021) issued a report identifying the most prominent 5G NEM vendors as of early 2021 in terms of technical features, producing a list including Cisco, Ericsson, Fujitsu, Huawei, Mavenir, NEC, Nokia, Samsung, and ZTE (pp. 2-7). This list, by itself, provides a good first order estimate in answering our first research question. However, we were interested in understanding the dimensions of the industry according to the seven factors identified by Chiasson and Davidson (2005), so we sought out substantiating evidence (such as annual reports and 5G-related press releases) from the websites of each of the NEMs included in Gartner's list. We also sought out 5G-related news stories from the websites of telecommunications trade magazines such as FierceWireless.com, NetworkWorld.com, RCRwireless.com, and the technology news aggregator website TechMeme.com. Within a matter of weeks, we had collected hundreds of artifacts mentioning a diversity of 5G-related topics such as standards bodies including $3 \mathrm{GPP}$ and its seven member SDOs, collaborations between NEMs and other organizations such as universities and research institutes, and pilot testing of 5G installations involving local and state governments.

The Alliance for Telecommunications Industry Solutions (ATIS) is one of the seven SDOs comprising the $3 \mathrm{GPP}$ organization (3GPP, 2020). We reviewed the website and publicly accessible reports of ATIS during our data collection, and were intrigued by the organizational makeup of the "ATIS board-level members" list appearing in an ATIS overview document (ATIS, 2021). The ATIS board-level members include NEM companies such as Ciena, Cisco, Ericsson, Juniper, and Nokia. A SDO is an example of a meta-organization (Ahrne \& Brunsson, 2005; Gulati, Puranam, \& Tushman, 2012) by virtue of the fact that the SDO membership is comprised of other organizations that voluntarily participate in advancing the goals of the SDO. Social network analysis of jointly authored ATIS document contributions can reveal interactions among the ATIS members that shed light on the crossorganizational dynamics of the industry.

Market research firm Strategy Analytics estimates that more than 178,000 papers using 5G-related keywords were submitted to 3 GPP working groups during the 2016 to 2019 timeframe (Yang, 2020). This volume of artifacts makes obvious the need for researchers to employ big data software tools to conduct analysis, as manual review of 178,000 papers is infeasible. Our initial study was exploratory in nature, and hence we did not acquire big data analysis tools to conduct quantitative analysis of available data sets about the industry. We plan to conduct such analysis in later phases of our research.

Another realization we reached during our data collection was that many of the older (pre-2015) 5G news media articles referred to companies that no longer exist as independent organizations. This is illustrated by Figure 2, which highlights key acquisitions by Nokia of former NEM competitors Motorola and Alcatel-Lucent, as well as the mobile networks division of Siemens, during the 2011 to 2016 time frame (Carpenter \& Lazonick, 2017). 


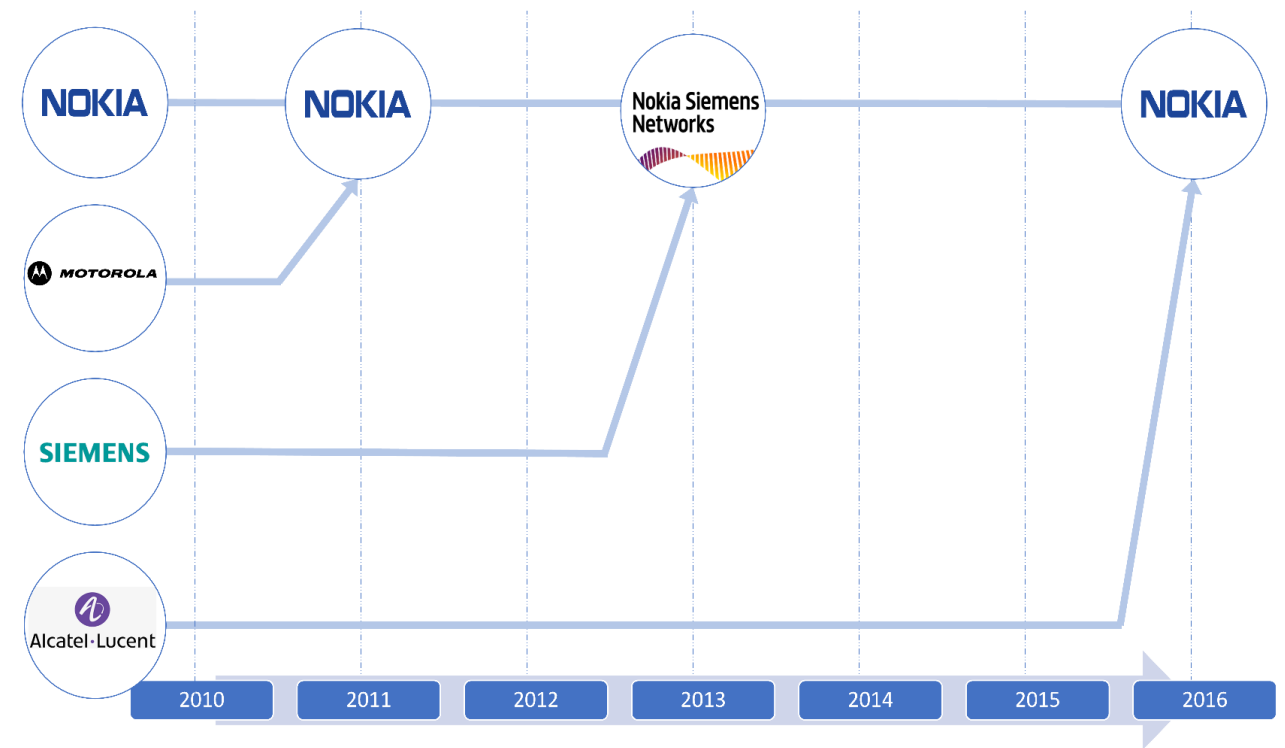

Figure 2: Major NEM acquisitions by Nokia, 2011 to 2016

A relatively small population of traditional telecommunications infrastructure equipment manufacturers currently dominates the 5G equipment market (Ericsson, 2018; GrayB, 2020; Yang, 2020), but entrants from other industries such as computer manufacturers including Dell and Hewlett Packard Enterprise appear to be altering the field (Koziol, 2021; Plantin, 2021; Townsend, 2019). Hence, the composition of firms in the 5G NEM industry is continuously changing in parallel with changes in the underlying $5 \mathrm{G}$ technologies.

\section{Discussion}

\section{GST as an overarching framework}

The original conception of general systems theory (GST) was to provide an alternate epistemological stance, moving away from a purely rationalist/deterministic frame and recognizing that living systems were prone to unpredictability and complexity (at a level that challenged observation and measurement), at the same time avoiding mystical explanations for phenomena. Conceptually, a given research program with a defined systems view tends to focus on some specific system, subsystem or particular set of attributes interactions of the same. We argue in this paper that the three frameworks presented in Section 2 - business ecosystems, large technological systems, and systems of systems are each analyzable under general system theory, and each can be viewed as subsets or subsystems of an industry system. Table 2 demonstrates the mapping of BE, LTS, and SoS properties to general system theory properties (Bertalanffy, 1968). Table 2 was truncated at publication time due to space limitations in this paper, but the full table is available at (Randall, Heffner, \& Lakshminarayan, 2021). 
Table 2: GST properties of BEs, LTS, and SoS

\begin{tabular}{|c|c|c|c|}
\hline $\begin{array}{c}\text { Property of } \\
\text { General } \\
\text { Systems }\end{array}$ & $\begin{array}{l}\text { Business Ecosystems } \\
\text { (Moore (1996)) }\end{array}$ & $\begin{array}{l}\text { Large Technical } \\
\text { Systems (van der } \\
\text { Vleuten, 2009) }\end{array}$ & $\begin{array}{c}\text { System of Systems } \\
\text { (Dahmann et al (2011)) }\end{array}$ \\
\hline Allometry & $\begin{array}{l}\text { Implied counter } \\
\text { argument that relative } \\
\text { growth rates for individual } \\
\text { "organisms" will depend } \\
\text { on the competitive } \\
\text { landscape. }\end{array}$ & $\begin{array}{l}\quad \text { Implied counter } \\
\text { argument that relative } \\
\text { growth rates will depend } \\
\text { on the competitive } \\
\text { landscape. }\end{array}$ & $\begin{array}{l}\quad \text { Growth is } \\
\text { incremental (p. 3). New } \\
\text { capabilities are available } \\
\text { to all participants, so } \\
\text { such growth in scale } \\
\text { could in turn lead to } \\
\text { growth in use. }\end{array}$ \\
\hline$\ldots$ & $\cdots$ & $\ldots$ & $\begin{array}{l}\text { [See (Randall et al., } \\
\text { 2021) paper addendum } \\
\text { for the full version of } \\
\text { this table] }\end{array}$ \\
\hline Sum & $\begin{array}{l}\text { The "organisms" } \\
\text { within the ecosystem and } \\
\text { the ecosystem itself are } \\
\text { continually coevolving. } \\
\text { (p. } 68 \mathrm{ff} \text { ) }\end{array}$ & $\begin{array}{l}\text { LTS coevolves with } \\
\text { the society within which } \\
\text { it is embedded. (p 219) } \\
\text { Emergent effects can be } \\
\text { both positive and } \\
\text { negative. }\end{array}$ & $\begin{array}{l}\quad \text { SoS is a purposeful } \\
\text { aggregate of } \\
\text { collaborating systems } \\
\text { (Maier, p.271). }\end{array}$ \\
\hline Wholeness & $\begin{array}{l}\text { Moore discusses } \\
\text { entwined entities } \\
\text { (businesses, customers, } \\
\text { government, etc.) with } \\
\text { cooperative relationships } \\
\text { at the core of an } \\
\text { ecosystem (p.28) }\end{array}$ & $\begin{array}{l}\text { "Because } \\
\text { components of a } \\
\text { technological system } \\
\text { interact, their } \\
\text { characteristics derive } \\
\text { from the system." } \\
\text { (Hughes (1987) p52) }\end{array}$ & $\begin{array}{l}\text { "... the resulting } \\
\text { system is the web of } \\
\text { individual } \\
\text { decisions by the } \\
\text { participants. (Maier, p. } \\
\text { 273) }\end{array}$ \\
\hline
\end{tabular}

For example, system of systems research looking at systems engineering perspectives and in recent times/period/papers particularly has been concerned with construction and management of purposeful technological systems, often in the context of military industrial applications. For other large organizational or industry applications our recent paper on Medicaid IT as a system of systems (Randall $\&$ Heffner, 2019) shows an example of these same ideas applied in a public health context.

\section{Managerial systems}

The three layer hierarchy of organizational systems comprising an industry system - technical, managerial, and institutional systems (Hirsch, 1972) - appears to have present day applicability when examining a technology-focused industry such as the 5G NEM industry. The applicability of the technical systems layer to the 5G NEM industry is somewhat obvious, as the entire reason for NEMs to exist is to manufacture the equipment that interconnects network operators to each other to form massive telecommunication networks spanning the globe. This section of the paper addresses the managerial systems layer, comprising the organizations which perform managerial functions such as finance, marketing, procurement, and logistics in support of the technical systems within each NEM company (Hirsch, 1972; Thompson, 1967). 


\section{Issues in Information Systems}

Volume 22, Issue 3, pp. 320-334, 2021

Our first observation is that the supply chains of each NEM appear to be managerial systems, fitting the definition of providing essential logistical services which enable technical systems telecommunication networks - to operate effectively (Cyberspace Solarium Commission, 2020; Daghar, Alinaghian, \& Turner, 2020; DHS CISA, 2020). When supply chains fail, as they did for both Nokia and Ericsson when a fire at a Philips' semiconductor plant occurred in 2000 (Tukamuhabwa, Stevenson, Busby, \& Zorzini, 2015), the effects on firm performance can be severe. We further observe that firm-to-firm telecommunications ecosystems (Rice \& Galvin, 2006) perform the role of being managerial systems for the larger industry that the firms belong to. Möller et. al, (2020) assert that many examples of empirical ecosystems are situated at an intermediate or "meso" level in between the firm level and the macro-economy level, which matches Hirsch's (1972) description of managerial systems within an industry system.

\section{Institutional systems}

One of the major sources of change affecting the current 5G NEM industry is a long-simmering trade conflict between the governments of the United States and China involving issues such as intellectual property protection and the cybersecurity of telecommunications equipment (Balding, 2019; Churchill, 2021; Donahue, 2020; Triolo, 2020). The governments of the United States and China are each institutional actors, and each is carrying out institutional logics to fulfil their national policies. The policies of the institutional actors have impacts on the individual NEMs within the industry, shaping which markets they can sell to and under what conditions. These institutional effects are clear evidence of a discernable institutional system within the 5G NEM industry.

Two other forms of institutional logics appear to have a dominant role in determining the structure and behaviors of the 5G NEM industry: The processes of standards bodies such as 3GPP and its seven regional SDOs (3GPP, 2021), and activities of the 21 consortia organizations comprising 3GPP's "Market Representation Partners" (3GPP, 2020; Teubner et al., 2021). The 21 consortia metaorganizations are arguably systems of organizational systems, since, logically, the individual member companies are organizational systems (Katz \& Kahn, 1966), and the combined meta-organizations exhibit Maier's (1998) SoS criteria of managerial and operational independence among the members. The effects of institutional-level actors such as SDOs on individual firms such as NEMs appears to be an area ripe for additional research.

\section{Implications and limitations}

This paper reintroduces the idea that industries can be studied using systems theory, and uses an example of a contemporary 2021 industry, the 5G NEM industry, to connect the concepts described by Hirsch (1972) to current IS theory and practice. We have argued that three frameworks from divergent disciplinary foundations, business ecosystems, large technological systems, and systems of systems, can be used to describe the system elements and system behaviors of a technology industry.

The limitations of this paper are manifold. First, this paper presents a conceptual discussion which establishes the foundations for a future empirical study. Second, the examples of public data evidence we have presented may be affected by selection bias, and non-public data such as the opinions and attitudes of influential individuals in the industry may contradict the assertions we have made in this paper. More detailed studies, as suggested in the next section, will be necessary to operationalize the ideas introduced in this paper.

\section{Conclusion and research agenda}

In this paper, we have reviewed Hirsch's (1972) construct of an industry system, related industry systems to more recent conceptualizations such as business ecosystems, large technological systems, and systems of systems, and have argued that each of these four frameworks is analyzable through general systems theory. We conclude in our initial exploratory phase of research that Hirsch's construct 


\section{Issues in Information Systems}

Volume 22, Issue 3, pp. 320-334, 2021

has received little attention in literature during the past ten years. Advances in the other three system frameworks presented can be re-integrated into the study of industries to provide a multi-disciplinary approach for analyzing industries as systems. We recommend the following research topics to advance research in industry systems:

\section{Business ecosystems as system elements in an industry system}

The construct of BEs appears to be ideally suited at a focal company plus immediate partners, or meso, level of analysis as argued by Möller et. al, (2020). The effects of localized BEs on a parent industry can be investigated further. A large BE, such as Ericsson's collection of SDO memberships, could be anticipated to have wider ranging effects on the NEM industry as a whole than the BE of a smaller $\mathrm{NEM}$, for example. BEs likely compete within high technology industries such as the 5G NEM industry reviewed in this paper. Modelling of the dynamic effects of BE competition and co-opetition on the evolution of their parent industry or industries is viable path for further research.

\section{Large technological systems as a rationale for explaining industry system evolution}

LTS concepts arguably address the institutional layer of an industry, but existing LTS literature does not attempt to relate the LTS framework to industry systems. The intertwining of history with contemporary events, referred to as path dependence in the complex systems literature (Mitleton-Kelly, 2003), appears to be well suited for analysis of industries through a LTS framework. Lai and Lin's (2017) literature review on organizational systems theory indicates that convergence of complex adaptive systems modeling and network modeling research can provide deeper insights into the behaviors of organizational systems. We concur with their assessment and suggest that their recommendations can be applied at the industry level.

\section{Organizational systems of systems at the industry level}

The SoS concepts of managerial independence and operational independence described by Maier (1998) arguably apply to collections of organizations within an industry, but few SoS authors have pursued that line of investigation. If the construct of SoS applies to organizations, as we believe it does, then analyzing industries as SoSs is a fruitful avenue of future research.

\section{References}

3GPP. (2020). 3GPP Partners. Retrieved June 2, 2021, from 3GPP.org website: https://www.3gpp.org/about-3gpp/partners

3GPP. (2021). About 3GPP Home. Retrieved June 2, 2021, from 3GPP.org website: https://www.3gpp.org/about-3gpp/about-3gpp

Adner, R. (2017). Ecosystem as structure: An actionable construct for strategy. Journal of Management, 43(1), 39-58. https://doi.org/10.1177/0149206316678451

Ahrne, G., \& Brunsson, N. (2005). Organizations and meta-organizations. Scandinavian Journal of Management, 21(4 SPEC. ISS.), 429-449. https://doi.org/10.1016/j.scaman.2005.09.005

Aldrich, H. E., \& Whetten, D. A. (1981). Organization-sets, action-sets, and networks: Making the most of simplicity. In P. C. Nystrom \& W. H. Starbuck (Eds.), Handbook of Organizational Design (Vol. 1). Retrieved from https://www.researchgate.net/publication/245024261 
ATIS. (2021). 2021 overview: Advancing ICT industry transformation. Retrieved from https://www.atis.org/wp-content/uploads/2021/02/2021-Overview.pdf

Auschra, C., Schmidt, T., \& Sydow, J. (2019). Entrepreneurial ecosystems as fields: Integrating mesolevel institutional theory. Zeitschrift Fur Wirtschaftsgeographie, 63(2-4), 64-78. https://doi.org/10.1515/zfw-2018-0016

Balding, C. (2019). Huawei Technologies' links to Chinese State Security Services. SSRN Electronic Journal. https://doi.org/10.2139/ssrn.3415726

Baron, J., \& Gupta, K. (2018). Unpacking 3GPP standards. Journal of Economics and Management Strategy, 27(3), 433-461. https://doi.org/10.1111/jems.12258

Beckert, J. (2010). How do fields change? the interrelations of institutions, networks, and cognition in the dynamics of markets. Organization Studies, 31(5), 605-627. https://doi.org/10.1177/0170840610372184

Bertalanffy, L. von. (1968). General system theory: Foundations, development, applications (Revised). New York: George Braziller.

Boulding, K. E. (1956). General systems theory-The skeleton of science. Management Science, 2(3), 197-208. https://doi.org/10.1287/mnsc.2.3.197

Bray, M., \& Waring, P. (2009). The (continuing) importance of industry studies in industrial relations. Journal of Industrial Relations, 51(5), 617-633. https://doi.org/10.1177/0022185609346174

Carpenter, M., \& Lazonick, W. (2017). Innovation, competition and financialization in the communications technology industry: 1996-2016. Retrieved from http://www.isigrowth.eu/wp-content/uploads/2017/06/working_paper_2017_08.pdf

Chiasson, M. W., \& Davidson, E. (2005). Taking industry seriously in information systems research. MIS Quarterly, 29(4), 591-605. https://doi.org/10.2307/25148701

Churchill, O. (2021, March 13). Five Chinese firms, including Huawei and ZTE, designated as threats to US national security. South China Morning Post. Retrieved from https://www.scmp.com/news/world/united-states-canada/article/3125296/five-chinese-firmsincluding-huawei-and-zte

Cilliers, P. (2001). Boundaries, hierarchies and networks in complex systems. International Journal of Innovation Management, 05(02), 135-147. https://doi.org/10.1142/s1363919601000312

Cook, S. C., \& Pratt, J. M. (2016). Typology dimensions for classifying SoSE problem spaces. 2016 11th Systems of Systems Engineering Conference, SSE 2016. https://doi.org/10.1109/SYSOSE.2016.7542962

Crowston, K., \& Myers, M. D. (2004). Information technology and the transformation of industries: Three research perspectives. Journal of Strategic Information Systems, 13(1), 5-28. https://doi.org/10.1016/j.jsis.2004.02.001 


\section{Issues in Information Systems}

Volume 22, Issue 3, pp. 320-334, 2021

Cyberspace Solarium Commission. (2020). Cyberspace Solarium Commission - Supply Chain White Paper. Retrieved from https://www.solarium.gov/public-communications/supply-chain-whitepaper

Daghar, A., Alinaghian, L., \& Turner, N. (2020). The role of collaborative interorganizational relationships in supply chain risks: A systematic review using a social capital perspective. Supply Chain Management. https://doi.org/10.1108/SCM-04-2020-0177

Dahmann, J. S., \& Baldwin, K. J. (2008). Understanding the current state of US defense systems of systems and the implications for systems engineering. 2008 2nd Annual IEEE Systems Conference, 1-7. https://doi.org/10.1109/SYSTEMS.2008.4518994

Dedrick, J., Kraemer, K. L., \& Linden, G. (2011). The distribution of value in the mobile phone supply chain. Telecommunications Policy, 35(6), 505-521. https://doi.org/10.1016/j.telpol.2011.04.006

Dersin, P. (2014). Technical Committee on 'Systems of Systems' - White Paper. IEEE-Reliability Society, (1), 1-5. Retrieved from https://rs.ieee.org/technical-activities/technicalcommittees/systems-of-systems.html

DHS CISA. (2020). Information and communications technology supply chain risk management task force year 2 report. Washington, DC.

DiMaggio, P. J., \& Powell, W. W. (1983). The iron cage revisited: Institutional isomorphism and collective rationality in organizational fields. American Sociological Review, 48(2), 147-160. https://doi.org/10.1016/S0742-3322(00)17011-1

Donahue, T. (2020). The worst possible day: U.S. telecommunications and Huawei. Prism : A Journal of the Center for Complex Operations, 8(3), 14-35. Retrieved from https://ndupress.ndu.edu/Portals/68/Documents/prism/prism_8-3/prism_8-3_Donahue_1435.pdf

Dutton, W. H., Schneider, V., \& Vedel, T. (2011). Large technical systems as ecologies of games: Cases from telecommunications to the Internet. SSRN Electronic Journal. https://doi.org/10.2139/ssrn.1141393

Ericsson. (2018). Estimating the future 5G patent landscape. Retrieved from https://www.ericsson.com/4a79f3/assets/local/patents/estimating-the-future-5g-patentlandscape.pdf

Fixson, S. K., \& Park, J. K. (2008). The power of integrality: Linkages between product architecture, innovation, and industry structure. Research Policy, 37(8), 1296-1316. https://doi.org/10.1016/j.respol.2008.04.026

Fung, B. (2019, April 10). China's Huawei bigfooted U.S. companies in 5G technology. Washington Post. Retrieved from https://www.washingtonpost.com/technology/2019/04/10/us-spat-withhuawei-explained/

Gartner. (2021). Magic Quadrant for 5G network infrastructure for communications service providers. Retrieved from https://www.gartner.com/en/documents/3997046/magic-quadrant-for-5gnetwork-infrastructure-for-communi 
Gharajedaghi, J. (2011). Systems thinking: Managing chaos and complexity: A platform for designing business architecture. Burlington, MA: Morgan Kaufmann.

GrayB. (2020). Exploration of 5G standards and preliminary findings on essentiality. Retrieved from https://info.greyb.com/hubfs/Downloadable_Reports/5G Report - 1st Release.pdf

Gulati, R., Puranam, P., \& Tushman, M. (2012). Meta-organization design: Rethinking design in interorganizational and community contexts. Strategic Management Journal, 33(6), 571-586. https://doi.org/10.1002/smj.1975

Hannan, M. T., \& Freeman, J. (1977). The population ecology of organizations. American Journal of Sociology, 82(5), 929-964. https://doi.org/10.1086/226424

Hirsch, P. M. (1972). Processing fads and fashions: An organization-set analysis of cultural industry systems. American Journal of Sociology, 77(4), 639-659. https://doi.org/10.4324/9780203993026

Hughes, T. P. (1983). Networks of power: Electrification in Western society, 1880-1930 (Vol. 2). Baltimore, MD: Johns Hopkins University Press.

Jabagi, N., Park, A., \& Kietzmann, J. (2020). The 5G revolution: Expectations versus reality. IT Professional, 22(6), 8-15. https://doi.org/10.1109/MITP.2020.2972139

Jacobides, M. G. (2005). Industry change through vertical disintegration: How and why markets emerged in mortgage banking. Academy of Management Journal, 48(3), 465-498. https://doi.org/10.5465/AMJ.2005.17407912

Kast, F. E., \& Rosenzweig, J. E. (1972). General systems theory: Applications for organization and management. In Classics of Organizational Theory (pp. 302-315). Orlando, FL: Harcort Brace \& Company.

Katz, D., \& Kahn, R. L. (1966). The social psychology of organizations. New York, NY: John Wiley \& Sons.

Keysight Technologies. (2019). 5G terms and acronyms. Retrieved from https://www.keysight.com/us/en/assets/7018-06171/brochures/5992-2996.pdf

Kim, K. K., Ryoo, S. Y., \& Jung, M. D. (2011). Inter-organizational information systems visibility in buyer-supplier relationships: The case of telecommunication equipment component manufacturing industry. Omega, 39(6), 667-676. https://doi.org/10.1016/j.omega.2011.01.008

Koziol, M. (2021). The clash over 5G's first mile: The wireless industry is divided on Open RAN's goal to make network components interoperable. IEEE Spectrum, 58(5), 40-46. https://doi.org/10.1109/MSPEC.2021.9423816

Lai, C.-H., \& Huili Lin, S. (2017). Systems theory. In The International Encyclopedia of Organizational Communication (pp. 1-18).

https://doi.org/10.1002/9781118955567.wbieoc203

Lawrence, P. R., \& Lorsch, J. W. (1967). Differentiation and integration in complex organizations. Administrative Science Quarterly, 12(1), 47. https://doi.org/10.2307/2391211 
Maier, M. W. (1998). Architecting principles for systems-of-systems. INCOSE International Symposium, 6(1), 565-573. https://doi.org/10.1002/j.2334-5837.1996.tb02054.x

Mäntymäki, M., \& Salmela, H. (2017). In search of the core business ecosystem concept. 9th International Workshop on Software Ecosystems (IWSECO 2017), 103-113.

Mitleton-Kelly, E. (2003). Complex systems and evolutionary perspectives on organizations: The application of complexity theory to organisations. In Ten principles of complexity and enabling infrastructures. Bingly, UK: Emerald Publishing Limited.

Möller, K., Nenonen, S., \& Storbacka, K. (2020). Networks, ecosystems, fields, market systems? Making sense of the business environment. Industrial Marketing Management, 90, 380-399. https://doi.org/10.1016/j.indmarman.2020.07.013

Monge, P. R., \& Contractor, N. S. (1987). Emergent communication networks. In The New Handbook of Organizational Communication. https://doi.org/10.4135/9781412986243.n12

Moore, J. F. (1993). Predators and prey: a new ecology of competition. Harvard Business Review, 71(3), 75-86. https://doi.org/Article

Moore, J. F. (1996). The death of competition: Leadership and strategy in the age of business ecosystems. New York, NY: HarperCollins.

Oh, D.-S., Phillips, F., Park, S., \& Lee, E. (2016). Innovation ecosystems: A critical examination. Technovation. https://doi.org/10.1016/j.technovation.2016.02.004

Parsons, T. (1960). Structure and process in modern societies. Glencoe, IL: Free Press.

Plantin, J.-C. (2021). The political hijacking of open networking: The case of open radio access network. European Journal of Communication. Retrieved from http://eprints.lse.ac.uk/109858/

Porter, M. E. (1990). The competitive advantage of nations. New York, NY: Free Press.

Randall, R. G., \& Heffner, M. (2019). Medicaid IT as a system of systems. 2019 14th Annual Conference System of Systems Engineering (SoSE), 254-259. https://doi.org/10.1109/sysose.2019.8753878

Randall, R., Heffner, M., \& Lakshminarayan, V. (2021). Table 2: General Systems Theory properties of BEs, LTS, and SoS. https://doi.org/10.13140/RG.2.2.12549.68326

Rice, J., \& Galvin, P. (2006). Alliance patterns during industry life cycle emergence: The case of Ericsson and Nokia. Technovation, 26(3), 384-395. https://doi.org/10.1016/j.technovation.2005.02.005

Rowley, T., Behrens, D., \& Krackhardt, D. (2000). Redundant governance structures: An analysis of structural and relational embeddedness in the steel and semiconductor industries. Strategic Management Journal, 21(3), 369-386. https://doi.org/10.1002/(SICI)10970266(200003)21:3<369::AID-SMJ93>3.0.CO;2-M

Scaringella, L., \& Radziwon, A. (2018). Innovation, entrepreneurial, knowledge, and business ecosystems: Old wine in new bottles? Technological Forecasting and Social Change, 136, 5987. https://doi.org/10.1016/j.techfore.2017.09.023 
Scott, W. R. (2008). Institutions and organizations: Ideas and interests (3rd ed.). Thousand Oaks, CA: SAGE Publications.

Sun, C., \& Rose, T. (2015). Supply chain complexity in the semiconductor industry: Assessment from system view and the impact of changes. IFAC-PapersOnLine, 28(3), 1210-1215. https://doi.org/10.1016/j.ifacol.2015.06.249

Teubner, L. K., Henkel, J., \& Bekkers, R. (2021). Industry consortia in mobile telecommunications standards setting: Purpose, organization and diversity. Telecommunications Policy, 45(3). https://doi.org/10.1016/j.telpol.2020.102059

Thomas, L. D. W., \& Autio, E. (2020). Innovation ecosystems in management: An organizing typology. In Oxford Research Encyclopedia of Business and Management. https://doi.org/10.1093/acrefore/9780190224851.013.203

Thompson, J. D. (1967). Organizations in action. New York: McGraw-Hill.

Townsend, W. (2019, July). Who is "really" leading in mobile 5G, Part 4: Infrastructure equipment providers. Forbes. Retrieved from https://www.forbes.com/sites/moorinsights/2019/07/19/who-is-really-leading-in-mobile-5gpart-4-infrastructure-equipment-providers

Triolo, P. (2020). The telecommunications industry in US-China context: Evolving toward nearcomplete bifurcation. Retrieved from https://www.jhuapl.edu/Content/documents/TrioloTelecomms.pdf

Tukamuhabwa, B. R., Stevenson, M., Busby, J., \& Zorzini, M. (2015). Supply chain resilience: Definition, review and theoretical foundations for further study. International Journal of Production Research, 53(18), 5592-5623. https://doi.org/10.1080/00207543.2015.1037934

U.S. Census Bureau. (2017). North American Industry Classification System. Retrieved from https://www.census.gov/econ/isp/sampler.php?naicscode=22\&naicslevel=2

van der Vleuten, E. (2009). Large Technical Systems. In A Companion to the Philosophy of Technology. West Sussex, UK: John Wiley \& Sons, Inc.

Von Bertalanffy, L. (1972). The history and status of General Systems Theory. Academy of Management Journal, 15(4), 407-426. https://doi.org/10.5465/255139

Yang, G. (2020). Who are the leading players in 5G standardization? An assessment for 3GPP 5G activities. Retrieved from https://www.strategyanalytics.com/access-services/serviceproviders/networks-and-service-platforms/reports/report-detail/who-are-the-leading-playersin-5g-standardization-an-assessment-for-3gpp-5g-activities

Approved for Public Release, Distribution Unlimited. Public Release Case Number 21-1682

The affiliation of the authors with The MITRE Corporation is provided for identification purposes only and is not intended to convey or imply MITRE's concurrence with, or support for, the positions, opinions, or viewpoints expressed by the authors.

(C2021 The MITRE Corporation. ALL RIGHTS RESERVED 